\title{
Otimizando a Transmissão TCP para Veículos Aéreos Não Tripulados
}

\author{
Rafael de Amorim Silva ${ }^{1}$, Leandro de Melo Sales ${ }^{1}$ \\ ${ }^{1}$ Instituto de Computação - Universidade Federal de Alagoas (UFAL) \\ Caixa Postal 57.072-900 - Maceió - AL - Brasil \\ \{rafael, leandro\}@ic.ufal.br
}

\begin{abstract}
This paper proposes a disruption-tolerant communication system for unmanned aerial vehicles that utilizes information from lower layers to control the transmission of TCP in disruptive channels. We adopt the suite ATN/IPS as a baseline, developing entities in the mobile router and in the controller host to perform this control. We discuss some technical details that must be considered to develop a draft for the IETF.
\end{abstract}

Resumo. Este artigo propõe um sistema de comunicação tolerante a interrupções para veículos aéreos não tripulados que utilizam informações provenientes das camadas inferiores da arquitetura TCP/IP para controlar a transmissão deste TCP em canais intermitentes. Utiliza-se a suíte de protocolos do padrão ATN/IPS como base, desenvolvendo e colocando entidades no roteador móvel e no host controlador para desempenhar tal controle. Também são discutidos detalhes técnicos que devem ser considerados para se desenvolver um esboço de padrão para o IETF.

\section{Introdução}

Nos últimos anos, há um crescente interesse da indústria e dos centros de pesquisa no desenvolvimento e na manutenção dos veículos aéreos não tripulados (Unmanned Aerial Vehicles ou UAV). Basicamente, um UAV consiste em uma aeronave sem pilotos, sendo controlada a distância por controladores ou de forma autônoma. Tais veículos podem ser utilizados para diversos fins, como por exemplo, em operações militares, na transmissão de eventos esportivos, no sensoriamento de florestas, na prática agro-pecuária, entre outros. Em muitas dessas aplicações, há uma demanda crescente pela oferta de transmissão multimídia de qualidade.

Segundo [Chao et. al, 2010], os principais protocolos utilizados para suprir tal demanda são derivados da arquitetura de Internet, sendo o Transmission Control Protocol ou TCP (oferecendo uma entrega confiável dos dados) e protocolos construidos na camada de aplicação utilizando o UDP (transmissão sem entrega confiável) como base. Os mecanismos de retransmissão permitem que um protocolo de transporte tolere interrupções durante uma comunicação, evitando um rápido encerramento de sua sessão. O protocolo TCP, por exemplo, implementa um mecanismo de retransmissão que tolera um certo período de interrupção. Este mecanismo implementa um temporizador para adiar a entrega, tolerando atrasos ou interrupções em uma comunicação entre UAV e controlador. 
Entretanto, o uso deste mecanismo em cenários com grandes interrupções pode reduzir o desempenho de transmissão desta rede, afetando a vazão do sistema, aumentando as retransmissões desnecessárias e o consumo de energia além de deixar o sistema mais ocioso. Por exemplo, um UAV está programado para transmitir um dado evento esportivo e deve sobrevoar uma determinada área para realizar o serviço de filmagem. Entretanto, o deslocamento da aeronave aliado a cobertura insuficiente da rede compromete a qualidade na transmissão do sinal, causando uma transmissão cortada ou com períodos de interrupção, Neste caso, é importante que a UAV tenha um protocolo de transporte sensível a perda de conectividade e que saiba adequadamente lidar com os efeitos negativos da interrupção na transmissão do TCP ou de outro protocolo de transporte.

Alguns trabalhos reduzem os efeitos indesejáves da perda momentânea de conectividade de um enlace utilizando uma técnica que congela temporariamente a janela de congestão do TCP, impedindo que pacotes sejam retransmitidos desnecessariamente. Dois trabalhos se destacam na aplicação destas técnicas: (i) FreezeTCP [Goff et.al, 2000] e (ii) DTP [Go et. al, 2012]. A primeira técnica é utilizada especialmente no processo de handoffs, isto é, quando um host móvel sai da sua estação atual e entra em outra cobertura de uma nova estação. Durante esta transição, o TCP zera a sua janela de congestão e aguarda o processo de handoff ser concluído, para retomar a sua transmissão. A segunda técnica implementa um mecanismo próprio de mobilidade em sua camada de transporte para mascarar as falhas na rede preterida. Neste caso, o host móvel efetua o congelamento da transmissão e o nó correspondente executa o mecanismo de retransmissão do TCP. Embora efetivos em alguns cenários, o ambiente aeronáutico é altamente dinâmico e exige novas adaptações na arquitetura TCP/IP para suportar apropriadamente transmissões de qualidade em cenários com conectividade intermitente.

Portanto, este artigo propõe uma abordagem para mitigar tais efeitos durante o voo de uma UAV dentro de uma determinada estação aéreo-terrestre (Air-to-Ground ou ATG), descrevendo uma abordagem que controla transmissões intra-celulares em cenários com longas interrupções na comunicação entre estações ATG e aeronaves. Especificamente, a abordagem insere 2 entidades na rede para realizar o controle da transmissão e a notificação sobre os estados de conectividade entre aeronave e estação terrestre. O TCP, sendo controlado por tais entidades, congela sua janela de congestão durante uma interrupção de enlace em uma célula ATG, permitindo que não haja retransmissões desnecessárias. A abordagem consegue obter um desempenho superior em relação ao uso de um tradicional TCP em cenários de transmissão aeronáutica.

O resto deste trabalho é apresentado da seguinte maneira: Seção 2 descreve os trabalhos relacionados com a proposta deste artigo. Seção 3 descreve a proposta deste trabalho, detalhando o mecanismo de retransmissão do TCP e as mudanças efetuada na arquitetura para permitir uma tolerância mais acurada nas interrupções aeronáuticas. Seção 4 apresenta as propostas para padronização desta arquitetura para o IETF. A Seção 5 apresenta as considerações finais deste trabalho. 


\section{Fundamentação}

A técnica de congelamento da janela de congestão do TCP tem sido uma técnica efetiva para diversas aplicações na literatura, embora o seu uso exija cuidados importantes no projeto e na implantação de uma arquitetura de rede apropriada para suportá-la. Neste caso, é importante conhecer a natureza das interrupções aeronáuticas para eficazmente projetar uma arquitetura capaz de lidar com estas. Esta seção relata alguns problemas associados à estas interrupções e descreve alguns trabalhos relacionados que tentam resolver parte destes problemas.

\subsection{Relato do Problema}

Redes intermitentes consistem em interrupções no canal aeronáutico devido a perdas momentâneas de conectividade do enlace aéreo-terrestre. As interrupções podem ocorrer devido aos seguintes fatores [birrane et. al, 2011]:

- mobilidade das aeronaves: uma das causas mais prováveis de interrupção devese as mudanças frequentes do endereço IP de uma aeronave e a inexistência de antenas e filtros apropriados para tolerar altas taxas de erro de transmissão por causa da alta velocidade destas aeronaves;

- posicionamento inadequado das antenas: antenas devem ser direcionadas para cima para cobrir o espaço aéreo e melhorar o desempenho do canal de comunicação. Um posicionamento inadequado destas antenas pode criar buracos na cobertura da rede, permitindo o surgimento das interrupções;

- interferências: dentro e entre estações onde há cobertura e, portanto, transmissão. Podem derrubar a conectividade de um enlace e criar interrupções;

- restrições de energia: Falhas na energia e problemas com cobertura da rede devido à qualidade do sinal reduz a capacidade de transmissão das redes aéreoterrestres;

- distribuição irregular das estações.

O mecanismo de controle do congestionamento do TCP é sensível a perda de pacotes na rede devido à interrupções na comunicação, reduzindo sua capacidade de transmissão precipitadamente quando houver uma longa exposição de uma interrupção aeronáutica. Este mecanismo controla o fluxo de pacotes na rede, evitando que a rede se torne congestionada. A idéia é introduzir um pacote na rede apenas quando os pacotes antigos já terem sido entregues. O TCP implementa uma janela de congestão e dinamicamente altera o seu tamanho. Isto ocorre porque o TCP supõe que a principal razão de um estouro de temporizador é devido à problemas de congestionamento da rede. Para controlar o fluxo, o TCP (versão NewReno) implementa 4 algoritmos que modificam o valor de sua janela de congestão ao longo de sua sessão, sendo eles [Floyd et. al, 2004]: 


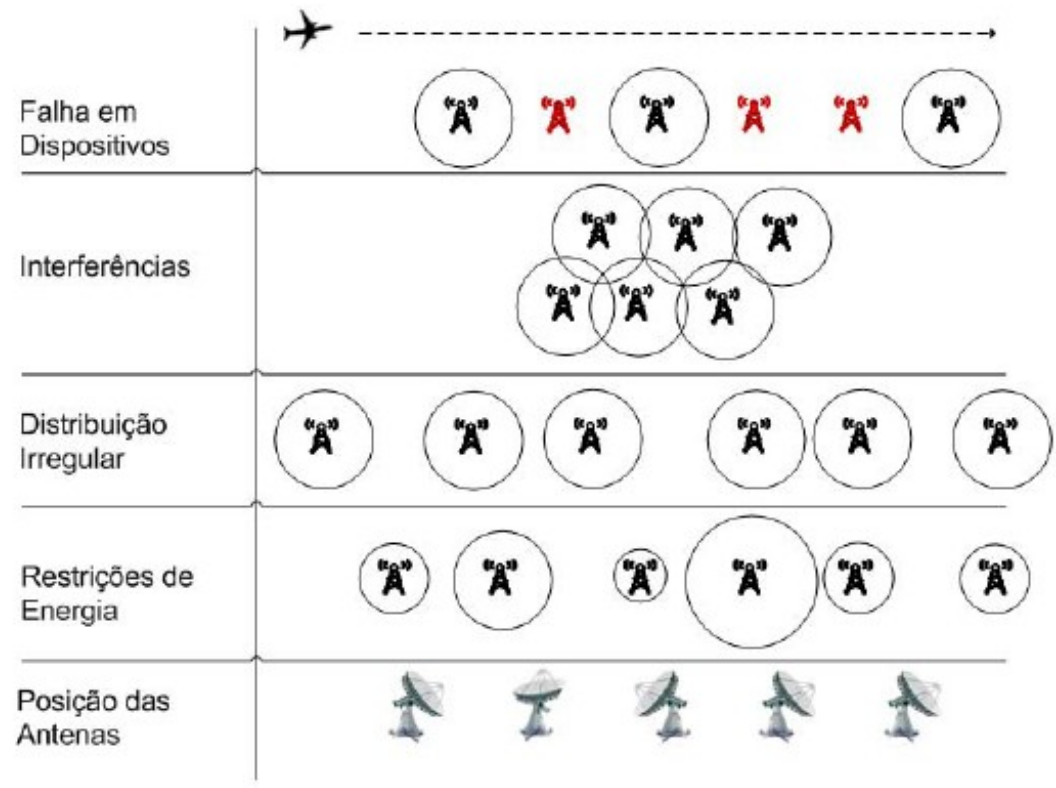

Figura 1. Tipos de interrupção aeronáutica.

- Slow Start (SS): este algoritmo é responsável por aumentar exponencialmente a janela de congestão quando um ACK é recebido até alcançar um determinado patamar pré-estabelecido. Isto permite controlar o fluxo de dados que está sendo inserido na rede, evitando que a rede se sobrecarregue com fluxos elevados.

- Congestion Avoidance (CA): este algoritmo aumenta linearmente a janela do transmissor quando um ACK é recebido até alcançar o patamar ou limite de largura de banda definido pelo receptor (Advertised Window ou AWND). Quando o congestionamento é detectado e pacotes são perdidos na rede, o estado deste controle retorna para o estado SS.

- Fast Retransmit (FRET): este algoritmo aprimora o controle de congestionamento por considerar ACKs duplicados como uma forma de alertar que um certo segmento está fora de ordem, replicado ou foi descartado pela rede. Depois que 3 ACKs forem duplicados, o algoritmo reenvia os pacotes antes que um timeout ocorra. Isto ajuda a reduzir o impacto dos longos timeouts em uma sessão TCP.

- Fast Recovery (FREC): algoritmo que governa a transmissão dos dados até que um ACK não duplicado seja recebido. A ideia é não forçar a mudança de estado para SS, pois o recebimento de ACKs duplicados indicam que a rede não está confiável, mas que ainda chegam pacotes ao destino.

\subsubsection{Consequências para a transmissão TCP}

A ocorrência de interrupções em ambientes aeronáuticos influencia protocolos como o TCP, limitando sua capacidade de transmissão, causando um maior consumo de energia para as aeronaves e causando o surgimento de retransmissões desnecessárias. Isto 
ocorre por causa dos estouros do temporizador de retransmissão e os atrasos na transmissão aeronáutica devido a estes estouros. Em primeiro lugar, os estouros de temporização ocorrem quando o mecanismo de retransmissão não recebe nenhuma informação do receptor, estourando o limite de tempo de espera. Neste caso, há um ajuste na janela de congestão (cai pela metade) e uma nova retransmissão é realizada. Quanto maior for tal interrupção, maior será o número de retransmissões ocorridas durante esta fase, gerando perdas na capacidade de transmissão do TCP, baixa eficiência energética e acréscimos no tempo de transferência de dados ao longo desta rede. Por outro lado, os atrasos de reinício ocorrem toda vez que o algoritmo backoff é executado, pois a transmissão apenas ocorre quando houver um estouro de temporização, levando a rede esperar por tal timeout. Caso a conectividade com o enlace aéreo-terrestre seja retomada, o mecanismo irá aguardar até o estouro acontecer, permitindo a incidência deste tipo de atraso. Em outras palavras, a utilização de probes periódicos implicam em longos tempos de espera para que o TCP possa realizar a transmissão dos dados. Tais problemas afetam os protocolos da camada de aplicação como o FTP, HTTP, SMTP e aplicações não interativas como transferência de arquivos, e-mails eletrônicos e aplicações Web, sendo essencial a utilização de uma arquitetura de rede que permita o retorno imediato da transmissão assim que o enlace ATG for reestabelecido, aumentando, portanto, a eficiência e a capacidade de transmissão da rede.

\subsection{Trabalhos Relacionados}

Esta seção descreve os trabalhos correlatos a técnica de congelamento da janela de congestão do TCP. O uso desta técnica para transmissões de UAVs em células ATG permite que retransmissões desnecessárias sejam mitigadas, o consumo de energia seja reduzido e o retorno de conectividade seja instantâneo. Dois trabalhos se destacam na implementação desta técnica: (i) Freeze-TCP [Goff et.al, 2000]; e (ii) DTP [Go et. al., 2012].

O Freeze-TCP proporciona o congelamento da janela de congestão quando handoffs são efetuados em uma rede de comunicação. Quando um host móvel sai de sua área de cobertura, um handoff na saída da estação é realizado com o transmissor, neste caso, zerando a sua janela de congestão e somente a descongelando após um novo handoff de entrada em uma nova estação ser feito. Isto reduz perdas de pacotes durante a fase de handoff.

O DTP é um protocolo de transporte desenvolvido para mascarar as falhas na rede preterida. O DTP possui um esquema de tolerância à interrupção através da implementação de um mecanismo próprio de mobilidade em seu núcleo de transporte. Assim como o Freeze-TCP, este protocolo também utiliza a técnica de congelamento da janela de congestão do TCP. No momento de interrupção da rede, o host móvel efetua o congelamento de sua transmissão e o nó correspondente executa o algoritmo tradicional de retransmissão, até que o parâmetro máximo de retransmissão seja alcançado e a conexão encerrada. A percepção de retorno de conectividade é feita por probes periódicos ou por mecanismos de captura como o netlink socket ou o broadcast receiver. Durante o handoff em uma estação, o mecanismo reconhece o novo IP adquirido pelo host móvel utilizando um processo de autenticação entre os hosts. A 
sessão é encerrada quando o timeout do keep alive estourar.

\subsection{Discussão}

Os trabalhos descritos anteriormente apresentam os seguintes problemas: (i) ambas as técnicas não consideram o ambiente em que um UAV está inserido, já que frequentes interrupções ocorridas dentro de uma célula de transmissão não necessariamente exige um processo de handoff cada vez que a conectividade for restabelecida. Embora permita transparência para as aplicações, para que esta técnica funcione, será necessário mudar a camada de transporte dos nós finais; (ii) A sessão TCP não pode ser descontinuada por causa destas interrupções, comprometendo seriamente a transmissão de grande quantidade de dados neste cenário. O DTP, em particular, pode não manter as variáveis de controle de sua sessão; (iii) o retorno de conectividade não pode ser feito por probes periódicos. Por isso, é essencial a elaboração de um protocolo de transmissão confiável que leve em conta as interrupções na conectividade e que aumente a capacidade da transmissão dos dados em uma rede aeronáutica utilizada para UAVs.

\section{TCP modificado para UAV}

Um protocolo de transmissão confiável localizado na camada de transporte da arquitetura ATN/IPS [ICAO, 2011] deve tolerar perdas de pacotes ou interrupções durante uma comunicação através do seu mecanismo de retransmissão. Um dos protocolos de transmissão confiável mais utilizados na Internet é o TCP [Jacobson et. al, 2014], o qual implementa um algoritmo de retardo da transmissão (backoff) toda vez que uma comunicação estiver com largos erros de pacote, tolerando um certo nível de interrupção na rede. Esta seção descreve uma arquitetura de rede que permita que o protocolo TCP possa receber informações cross-layer das camadas inferiores para controlar sua transmissão, utilizando a técnica de congelamento da janela de congestão.

\subsection{Descrição do Protocolo TCP}

O TCP é um protocolo de transporte robusto que provê um serviço de fluxo contínuo de bytes confiável. A transmissão é feita de forma bidirecional (a sessão permite o tráfego de dados tanto do transmissor ao receptor quanto do receptor ao transmissor). As principais funções deste protocolo são [Floyd et. al, 2004]:

- A entrega em ordem dos pacotes através do mecanismo de janela deslizante;

- O controle de congestionamento;

- O controle de fluxo dos dados, limitando a quantidade de dados que o transmissor pode enviar;

- Um mecanismo de retransmissão, garantindo a entrega de todos os pacotes a serem transmitidos.

O mecanismo de retransmissão do TCP implementa um algoritmo backoff para permitir uma maior tolerância em situações onde há perdas de pacotes devido a 


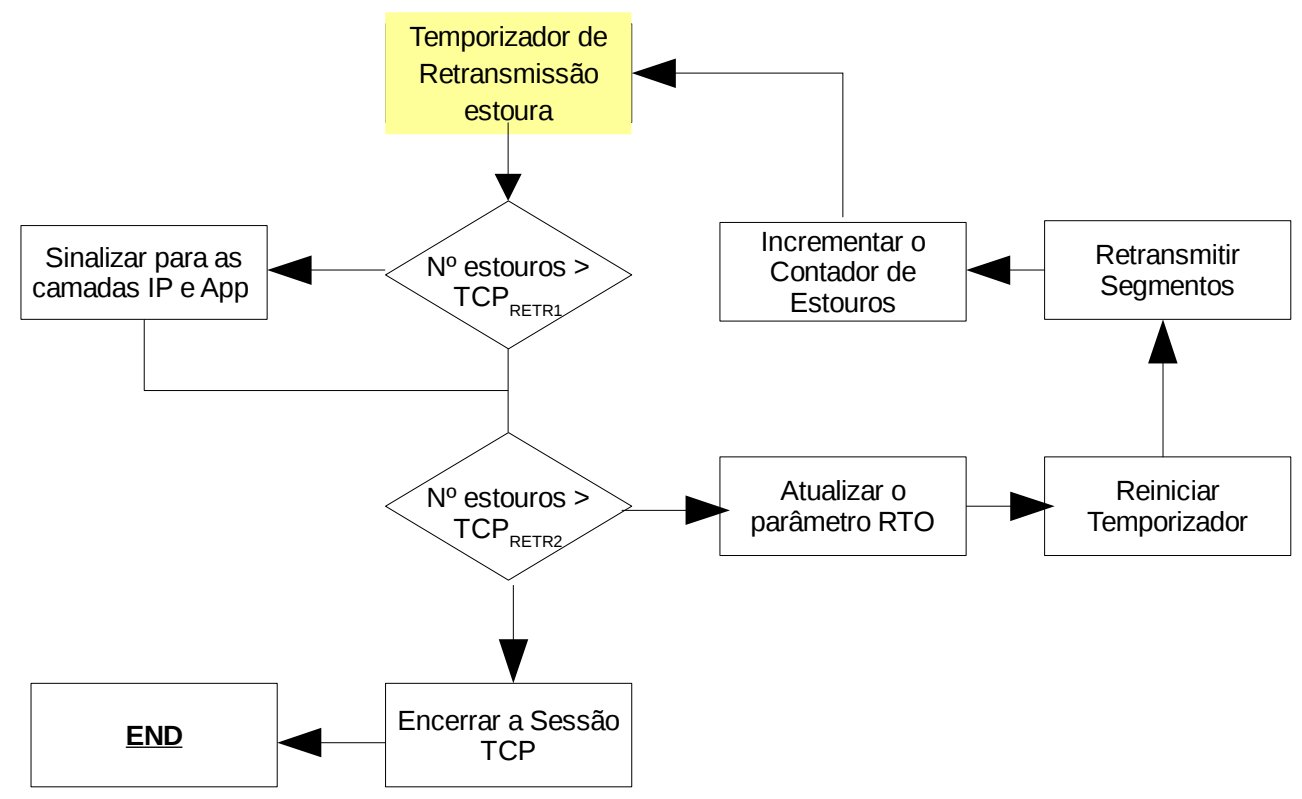

Figura 2. Fluxograma do Mecanismo de retransmissão do TCP.

redes congestionadas ou intermitências no canal. Este algoritmo possui um comportamento exponencial, o qual o retardo é aumentado exponencialmente até alcançar um patamar máximo $\left(\mathrm{RTO}_{\mathrm{Max}}\right)$ e um comportamento linear, aumentando linearmente o retardo depois que este patamar for alcançado. Além disso, um parâmetro $\left(\mathrm{n}_{\text {Max }}\right)$ determina o número máximo de retransmissões suportadas pelo mecanismo, encerrando a sessão do TCP assim que tal parâmetro for alcançado. A Equação 1 define esta tolerância e é baseada no trabalho [Caini et.al, 2009].

A Equação

$$
R T O(r)= \begin{cases}R T O_{\text {ini }} & \text { se } r=0 \\ 2 \times R T O(r-1) & \text { se } r<n_{\text {expo }} \\ R T O_{\max } & \text { se } n_{\text {expo }} \leq r \leq n_{\max }\end{cases}
$$

representa o valor do estouro de retransmissão (RTO) ao longo das (r) retransmissões ocorridas em um trecho interrompido, sendo que a primeira linha da equação representa o parâmetro inicial do RTO, a segunda linha representa o comportamento exponencial do mecanismo TCP e a terceira linha representa o seu comportamento linear.

O TCP instancia um temporizador para garantir que todos os pacotes sejam corretamente transmitidos, assegurando uma entrega de dados confiável. Este temporizador é iniciado com o parâmetro $\mathrm{RTO}_{\text {ini }}$ toda vez que o TCP enviar um pacote pela rede. Caso o transmissor receba uma confirmação de entrega pelo receptor (ACK), o temporizador é interrompido e reiniciado com o mesmo valor $\mathrm{RTO}_{\text {ini. }}$ Caso todos os pacotes sejam devidamente entregues com suas respectivas confirmações, o temporizador será desligado. Todavia, se existir pacotes na rede sem confirmação de 


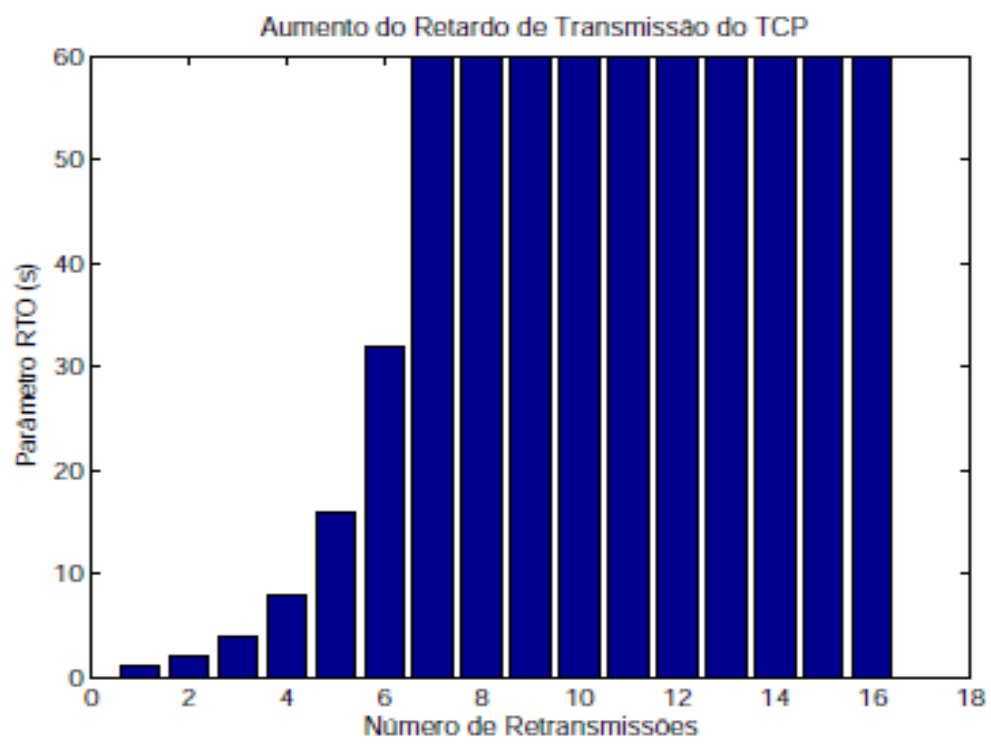

Figura 3. Algoritmo de Backoff do TCP.

entrega e este temporizador expirar, então o TCP retransmitirá os pacotes à espera de um ACK (segundo padrão Go Back n) e reiniciará o temporizador exponencialmente segundo a equação descrita anteriormente.

Esta operação acontece cada vez que o temporizador expira até o momento que este temporizador alcance o patamar máximo $\mathrm{RTO}_{\text {Max }}$ A partir deste ponto, o temporizador assume o valor $\mathrm{RTO}_{\text {Max }}$ constante até que o parâmetro $\mathrm{n}_{\text {Max }}$ seja alcançado. $\mathrm{O}$ parâmetro $\mathrm{TCP}_{\text {Retr } 1}$ é um patamar definido pelo TCP para alertar a camada IP sobre a interrupção, permitindo que esta camada inicie procedimentos específicos para tratar tal interrupção. $\mathrm{O}$ parâmetro $\mathrm{TCP}_{\text {Retr2 }}$ é o valor a ser associado ao $\mathrm{n}_{\max }$, representando o número máximo de retransmissões suportadas. Quando isto acontecer, o TCP encerra sua sessão e somente é possível reiniciar a transmissão com a intervenção da aplicação.

A Figura 3 ilustra um exemplo do comportamento obtido pela Equação 1 ao longo de uma interrupção. Ao longo de um trecho interrompido com $\mathrm{n}_{\mathrm{Max}}=16$, utilizase a Equação $\mathrm{RTO}_{(\mathrm{n})}=2 \mathrm{x}$ RTO (r-1) até que $r$ seja igual ao parâmetro $\mathrm{RTO}_{\mathrm{Max}}=60$. A partir deste ponto, cada retransmissão é calculada utilizando a Equação $\mathrm{RTO}_{(\mathrm{r})}=$

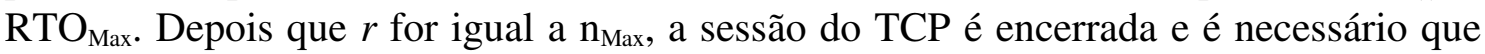
uma aplicação estabeleça uma nova sessão para continuar transmitindo dados. $\mathrm{O}$ eixo $\mathrm{X}$ representa o número de retransmissões ocorridas durante o trecho interrompido e o eixo Y representa o crescimento do parâmetro RTO ao longo deste trecho.

\section{Proposta de Adaptação do TCP para UAV}

Este artigo propõe uma arquitetura de rede adaptada para aumentar a capacidade de transmissão entre aeronaves e estações ATG. A arquitetura suporta a troca cross layer de mensagens entre camadas inferiores e camadas superiores da pilha MIPv6, fornecendo uma camada específica para controlar a transmissão de pacotes do TCP em cenários de interrupção. Esta arquitetura aumenta o desempenho de comunicação na 

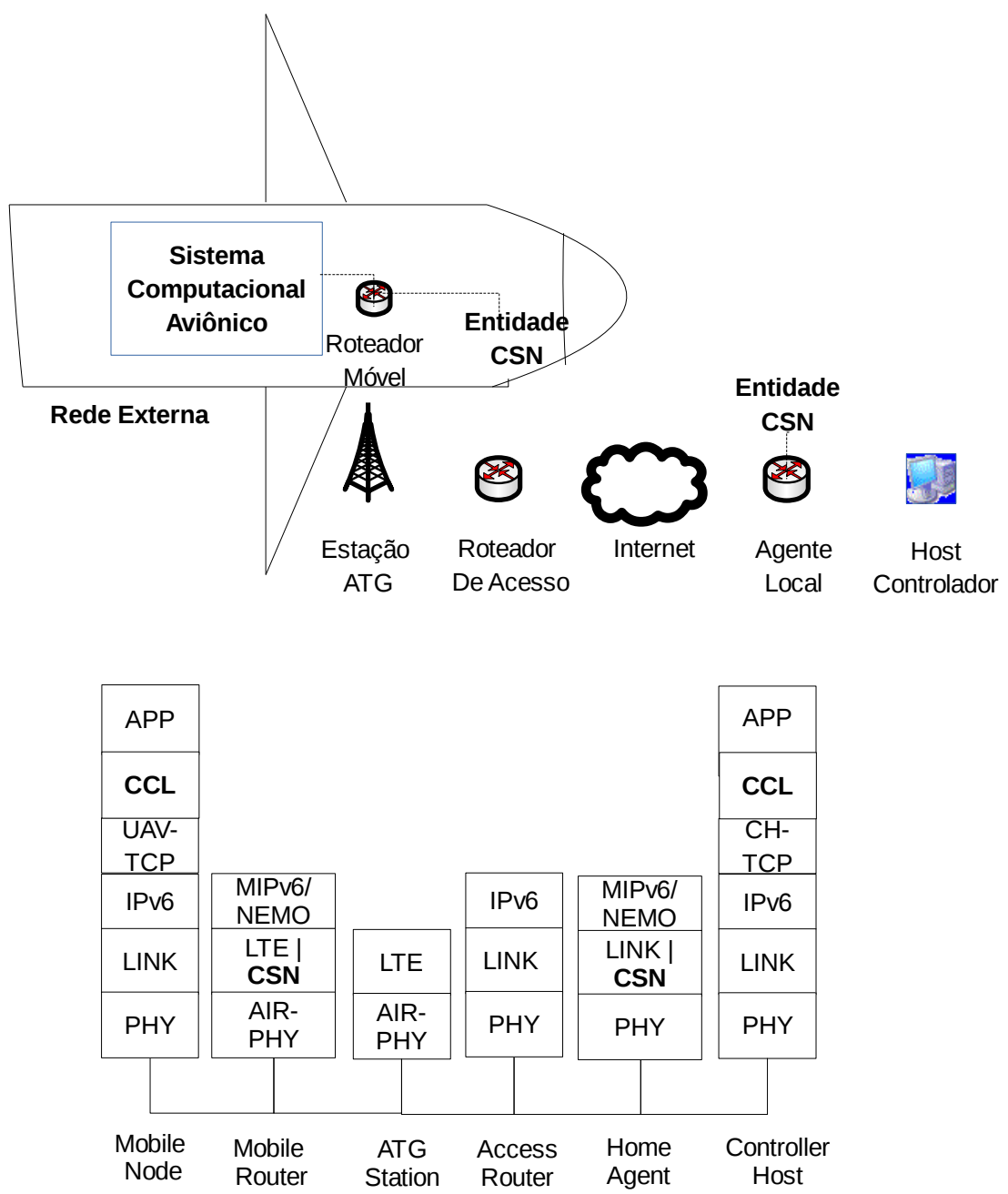

Figura 4. Arquitetura Proposta Neste Artigo para UAV.

rede, garantindo a qualidade de serviço e um alto padrão de transmissão. Diferentemente de trabalhos que consideram trajetórias de aeronaves baseadas em plano de voo [silva et. al, 2014], esta arquitetura direciona o ganho de desempenho para transmissões intra-celulares, onde não se tem informações sobre quando a conectividade entre aeronave e estação ATG será reestabelecida. Neste caso, uma arquitetura mais eficiente deve ser implementada para lidar com este cenário.

\subsection{Arquitetura de Rede}

A arquitetura proposta neste artigo utiliza o padrão ATN/IPS como sendo o seu modelo de referência [Ayaz et. al., 2009]. Os protocolos PMIPv6 [Johnson et. al., 2004], NEMO [Devarapalli et. al., 2005], Diffserv [Blake et. al., 1998], IEEE 802.21 [Taniuchi et. al, 2009] e Global HAHA (otimização na rede) são adotados nesta arquitetura segundo [Ayaz et. al, 2009]. Além disso, a tecnologia LTE é adotada como o padrão de comunicação entre a aeronave e as estações. Tal tecnologia é escolhida devido a sua elevada largura de banda e boa capacidade de transmissão com veículos de alta velocidade. Além destes protocolos, a arquitetura é composta por uma entidade de rede que notifica as camadas superiores sobre o status da conectividade do enlace e uma camada de convergência que implementa uma máquina de estados para controlar a 


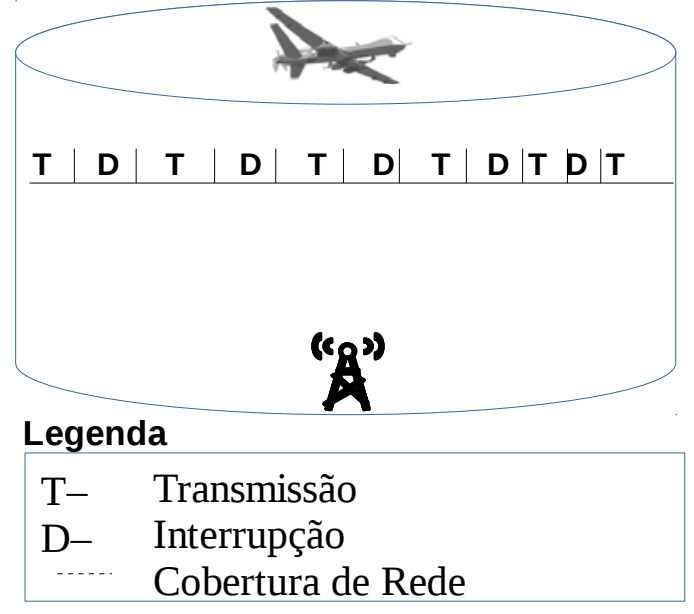

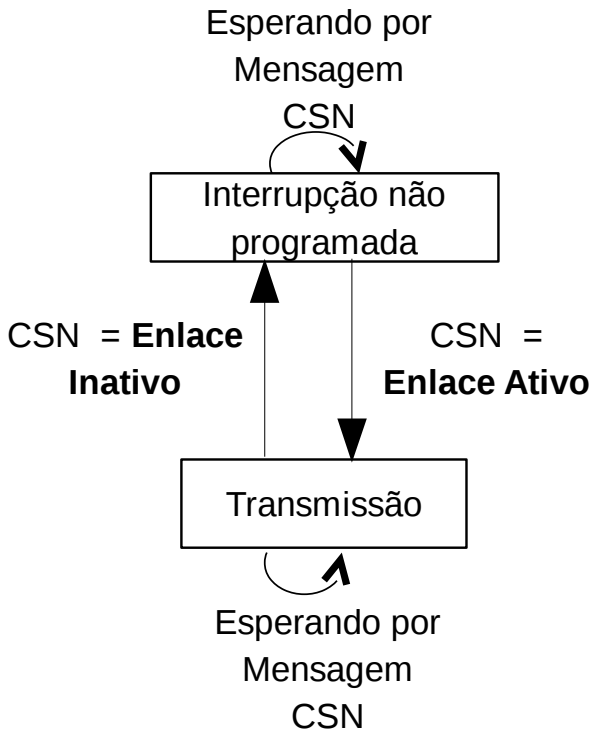

Figura 5. Comportamento da Arquitetura Proposta neste Artigo durante Transmissão intra-celular.

transmissão do TCP. A Figura 4 ilustra a pilha de protocolos utilizada na arquitetura proposta. Note que a camada de convergência controla o TCP da UAV (UAV-TCP) e o TCP do Host Controlador (CH-TCP). Tanto o roteador da aeronave quanto o agente local da pilha PMIPv6 implementa a entidade notificadora (CSN), sendo essencial para a identificação de interrupções durante o voo de uma UAV. Os demais protocolos são detalhados em [Ayaz et. al, 2009].

\subsubsection{Notificador do estado de conectividade}

O notificador de conectividade (Connectivity Status Notifier ou CSN) é uma entidade da rede que permite que uma camada de convergência saiba sobre o atual estado de conectividade de enlace do seu host. O foco desta entidade é informar, para as camadas superiores, se há ou não interrupções na comunicação. Tanto a aeronave quanto os agentes locais são modificados para suportar esta operação. Esta entidade provê o estado atual do enlace (i.e. se está ativo ou não) e o endereço MAC (Medium Access Control) da atual estação. Este endereço permite que aplicações da camada superior da pilha de protocolos saibam em qual estação a aeronave se encontra, servindo também para estimar a localização atual da aeronave.

A entidade CCL utiliza as informações processadas pela entidade CSN para realizar a mudança de estado em sua máquina de estados. Para tal, a entidade CCL muda o estado de interrupção para transmissão quando a mesma recebe uma informação positiva de conectividade da entidade CSN ou muda o estado de transmissão para interrupção quando a mesma recebe uma informação negativa de conectividade da entidade CSN. A entidade CSN envia suas mensagens ICMP através da técnica crosslayer, estabelecendo uma comunicação direta entre as outras entidades. O protocolo IEEE 802.21 [Taniuchi et. al, 2009] é utilizado como base para prover os serviços ofertados por esta entidade. 


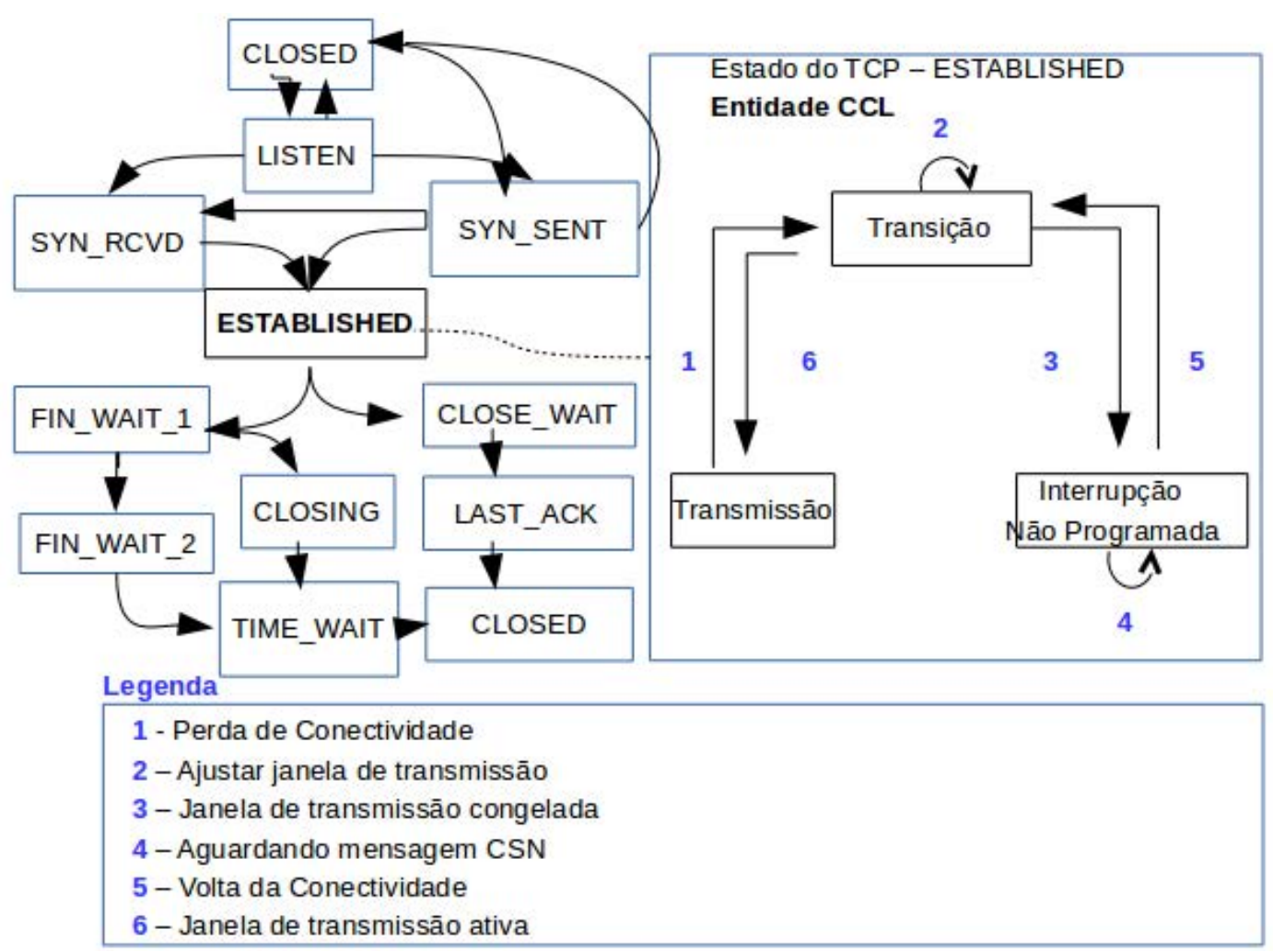

Figura 6. Máquina de Estados do TCP (à esquerda) e o uso da camada de convergência para Controle do TCP (à direita).

\subsubsection{Controlador da Camada de Convergência}

O controlador da camada de convergência (CCL) é responsável por controlar a transmissão do TCP durante o voo de uma UAV. Esta entidade modifica o TCP para minimizar os impactos das interrupções aeronáuticas, estabelecendo um sincronismo de transmissão entre os TCPs finais para aumentar a capacidade de transmissão da rede. Tal entidade é dividida em três módulos principais:

- Máquina de Estados: controla a transmissão, permitindo reduzir as retransmissões e os atrasos de reinicio na comunicação. Esta entidade instancia e controla os temporizadores de transmissão e interrupção ao longo de cada segmento de rota, obtendo regularmente informações sobre o estado de conectividade do enlace. A informação do estado de enlace é necessária para realizar a transição entre os estados de transmissão e interrupção.

- Ajustador da Janela de Congestão: este módulo é ativado no estado de transição do TCP, efetuando alterações na janela de transmissão do TCP para otimizar o desempenho da rede aeronáutica.

- Gerenciador de Mensagens: este módulo recebe, envia e processa mensagens de sinalização entre os TCPs modificados para sincronizar os tempos de transmissão e interrupção do sistema aviônico com o sistema terrestre. O módulo recebe mensagens ICMP da entidade CSN sobre o estado de conectividade do enlace, necessário para se realizar a mudança entre os estados implementados na máquina de estados.

As mudanças de estado devem ocorrer quando ou o temporizador de transmissão 
expirar e quando a notificação de estado do enlace for recebida. A máquina de estados define 3 estados para controlar o TCP em cenários aeronáuticos: (i) estado de transmissão; (ii) estado de transição; e (iii) estado de interrupção não programada.

- No estado de transmissão, permitem-se que os dados sejam transmitidos durante o sobrevoo de uma aeronave em uma estação ATG. O estado de transmissão utiliza os parâmetros convencionais de retransmissão do TCP e efetua a comunicação com a rede de acesso. Além disso, permite a troca de mensagens de sinalização entre os módulos primários e secundários.

- No estado de transição, a janela de congestão é modificada para congelar ou reiniciar a transmissão, sendo o seu valor armazenado como uma variável de sessão do TCP.

- No estado de interrupção não programada, $O$ estado só muda quando o enlace detectar novamente a conectividade. Este estado é ativado quando o enlace perde sua conectividade durante a fase de transmissão. Nesta técnica, não há necessidade de sincronismo, pois a janela de congestão, em um trecho interrompido, estará congelada até quando a máquina de estados receber uma notificação do estado de enlace, decidindo pela mudança de estado. A eficiência, neste caso, estará ligada ao agente CSN, pois este decidirá quando a janela de congestão será alterada. Os pacotes keep alive devem ser controlados para o correto funcionamento.

\subsection{Operação}

A operação da rede é descrita como segue. A CCL é responsável por controlar os parâmetros da sessão, decidindo quando a janela de congestão é congelada ou estabelecida. A camada de enlace de uma célula ATG envia mensagens de sinalização do Ipv6 contendo o estado do enlace ATG atual (i.e. ativo, interrompido, falho) para a camada de convergência situada no UCH-TCP. Neste caso, o temporizador de transmissão ainda está rodando e uma informação de não conectividade é enviada pela entidade CSN. A partir do momento em que a entidade CSN enviar tal informação, o TCP deverá mudar do estado de transmissão para estado de transição, zerando sua janela de congestão e mudando novamente para o estado de interrupção não programada, ficando no aguardo do retorno de conectividade. Este estado permite que o TCP obtenha desempenhos superiores quando as interrupções não forem previstas durante a fase de transmissão. Isto permite que não haja retransmissão e que a janela de congestão permaneça inalterada após o retorno da transmissão.

\section{Propostas para padronização pela IETF}

A Força tarefa de engenharia da Internet consiste em um grupo de pessoas que colaboram para a engenharia e a evolução das tecnologias de Internet. Este grupo elabora as especificações de novos padrões de Internet, não havendo uma corporação por trás nem membros ou diretores. Seu objetivo é identificar e propor soluções para problemas técnicos da Internet, especificando o desenvolvimento ou o uso de protocolos.

A padronização das entidades de rede inseridas na arquitetura discutida neste artigo deve ser realizada da seguinte forma: 
1. Padronização da Arquitetura $\rightarrow$ A IETF tem documentos do tipo informativo que servem para formalizar arquiteturas, plataformas, entre outros. Neste caso, a arquitetura proposta para UAV poderia ser padronizada utilizando suas entidades de rede e a integração entre os vários protocolos IETF envolvidos.

2. Padronizar a entidade notificadora $\rightarrow$ Esta entidade requer regras para atualização de estados da máquina TCP e para solicitação e recebimento de mensagens vindas de outras entidades.

3. Padronizar a entidade controladora $\rightarrow$ Esta entidade requer regras para realizar a comunicação entre a entidade notificadora e uma aplicação controladora.

\section{Considerações Finais}

Este artigo propôs uma arquitetura de rede para UAV projetada para suportar longas interrupções na comunicação aeronáutica. Esta abordagem consistiu em adicionar uma entidade de rede que controla a transmissão através de notificações emitidas por outra entidade de rede instalada na camada de enlace, mitigando as retransmissões e os atrasos na transmissão de dados ocasionados pelo inadequado funcionamento do TCP em cenários de comunicação intermitente. Embora este artigo tenha investigado o uso da arquitetura em um cenário de transmissão UAV intra-celular, é possível estendê-los para outros tipos de cenários e serviços como:

- Comunicação Aeronáutica: A arquitetura proposta neste trabalho pode ser adaptada para fornecer serviços de comunicação aeronáutica. Para tal, é necessário que suas aplicações não possuam restrições de tempo (o que acontece com serviços de mensagens, típicos dos serviços de tráfego aéreo e controle operacional da aeronave).

- Redes de alta altitude: é possível adaptar a arquitetura proposta para sincronizar as transmissões por meio do uso de balões.

- Redes de satélites: pode-se utilizar informações referentes a navegação de uma constelação de satélites para realizar transmissão de dados. No entanto, altos RTTs e baixo desempenho da comunicação devido a ruídos prejudicam a qualidade do canal.

- Redes veiculares: A arquitetura proposta pode aumentar a capacidade de transmissão adequando-se os parâmetros do TCP, sendo útil para inúmeras aplicações em trens, ônibus ou carros, por exemplo.

As seguintes contribuições são destacadas: (i) transmissão otimizada, sendo o controle realizado por uma camada overlay, não sendo obrigatória a modificação do TCP; (ii) economia de energia de uma UAV, já que retransmissões são mitigadas; (iii) ao longo de uma transmissão intra-celular, a vazão de pacotes é amplificada, melhorando o desempenho da rede. Portanto, a arquitetura de rede proposta proporciona uma melhora na capacidade de transmissão e na transferência de dados ao longo de uma comunicação UAV, aumentando significativamente a eficiência deste sistema. 


\section{Referências}

H. Chao, Y. Cao, and Y. Chen, "Autopilots for small unmanned aerial vehicles: a survey", Int. J. Control, Automation and Systems", Springer, vol. 8, pp. 36-44, 2010.

S. Ayaz, C. Bauer, C. Kissling, F. Schreckenbach, F. Arnal, C. Baudoin, K. Leconte, M. Ehammer, and T. Graeupl, "Architecture of an IP-based Aeronautical Network", Integrated Communications, Navigation and Surveillance Conference, IEEE, pp. 1-9, 2009.

Jacobson, V., Braden, B., e Borman, D. (2014) "TCP extensions for high performance ", RFC 7323, IETF Standard.

ICAO (2011) "Manual for the ATN using IPS Standards and Protocols", Doc 9896, ICAO draft.

Caini, C., Cornice, P., Firrincieli, R., Livini, M. e Lacamera, D. (2009) "Analysis of TCP and DTN retransmission algorithms in presence of Channel Disruptions", In International Conference on Advances in Satellite and Space Communications, IEEE Publisher, Piscataway.

Silva, R.A., Netto, J.E., Paiva, M.A.C., Anzaloni, A. "Uma abordagem de Transmissões Programadas Atenta a Interrupções para Redes Aéreo-Terrestres", IEEE Latin America Transactions, v. 12, n. 8, p. 1409-1417, 2014.

Devarapalli, V., Wakikawa, R., Petrescu, A. e Thubert, P. (2005) "Network Mobility (NEMO) Basic Support Protocol", RFC 3963, IETF Standard.

Floyd, S., Gurtov, A. e Henderson, T. (2004) "The NewReno modification to TCP's fast recovery algorithm ”, RFC 2582, IETF Standard.

Johnson, D., Perkins, C. e Arkko, J. (2004) "Mobility support in IPv6 ”, RFC 3775, IETF Standard.

Blake, S., Black, D., Carlson, M., Davies, E., Wang, Z e Weiss, W (1998), “An Architecture for Differentiated Services ”, RFC 2475, IETF Standard.

Goff, T., Moronski, J., Phatak, D., Gupta, V. "Freeze-TCP: A true end-to-end TCP enhancement mechanism for mobile environments", Nineteenth Annual Joint Conference of the IEEE Computer and Communications Societies (INFOCOM), v.3, pp 1537-1545, 2000.

Go, Y., Moon, Y., Nam, G., Park, K. A disruption-tolerant transmission protocol for practical mobile data offloading, Proceedings of the third ACM international workshop on Mobile Opportunistic Networks, pp 61-68, ACM, 2012.

Birrane, III., Edward, J., Burleigh, S.C., Cerf, V. Defining tolerance: impacts of delay and disruption when managing challenged networks, Proceedings of AIAA Infotech@Aerospace Conference, 2011.

Taniuchi, K., Ohba, Y., Fajardo, V., Das, S., Tauil, M., Cheng, YH, Dutta, A., Baker, D., Yajnik, M., Famolari, D. IEEE 802.21: Media independent handover: Features, applicability, and realization, Communications Magazine, IEEE, v. 47, $\mathrm{n}^{\circ}$ 1, pp 112$120,2009$. 